\title{
How downstream sub-basins depend on upstream inflows to avoid scarcity: typology and global analysis of transboundary rivers
}

\author{
Hafsa Ahmed Munia ${ }^{1}$, Joseph H. A. Guillaume ${ }^{1}$, Naho Mirumachi ${ }^{2}$, Yoshihide Wada ${ }^{3}$, and Matti Kummu ${ }^{1}$ \\ ${ }^{1}$ Water and Development Research Group, Aalto University, Tietotie 1E, 02150 Espoo, Finland \\ ${ }^{2}$ Department of Geography, King's College London, Strand, London, WC2R 2LS, UK \\ ${ }^{3}$ International Institute for Applied Systems Analysis, Schlossplatz 1, 2361, Laxenburg, Austria
}

Correspondence: Hafsa Ahmed Munia (hafsa.munia@aalto.fi) and Matti Kummu (matti.kummu@aalto.fi)

Received: 31 August 2017 - Discussion started: 11 September 2017

Revised: 16 March 2018 - Accepted: 17 March 2018 - Published: 8 May 2018

\begin{abstract}
Countries sharing river basins are often dependent upon water originating outside their boundaries; meaning that without that upstream water, water scarcity may occur with flow-on implications for water use and management. We develop a formalisation of this concept drawing on ideas about the transition between regimes from resilience literature, using water stress and water shortage as indicators of water scarcity. In our analytical framework, dependency occurs if water from upstream is needed to avoid scarcity. This can be diagnosed by comparing different types of water availability on which a sub-basin relies, in particular local runoff and upstream inflows. At the same time, possible upstream water withdrawals reduce available water downstream, influencing the latter water availability. By developing a framework of scarcity and dependency, we contribute to the understanding of transitions between system regimes. We apply our analytical framework to global transboundary river basins at the scale of sub-basin areas (SBAs). Our results show that 1175 million people live under water stress (42\% of the total transboundary population). Surprisingly, the majority (1150 million) of these currently suffer from stress only due to their own excessive water use and possible water from upstream does not have impact on the stress status - i.e. they are not yet dependent on upstream water to avoid stress - but could still impact on the intensity of the stress. At the same time, 386 million people (14\%) live in SBAs that can avoid stress owing to available water from upstream and have thus upstream dependency. In the case of water shortage, 306 million people $(11 \%)$ live in SBAs dependent on upstream water to avoid possible shortage. The identification of transitions between system regimes sheds light on how SBAs may be
\end{abstract}

affected in the future, potentially contributing to further refined analysis of inter- and intrabasin hydro-political power relations and strategic planning of management practices in transboundary basins.

\section{Introduction}

While water is a renewable resource, its availability is finite. As population and water demand grow, water becomes scarce. If local precipitation is insufficient to meet needs, a region may draw on external water resources, both physical and virtual (through food and goods trade) (Hoekstra and Chapagain, 2011). External water resources constitute a considerable part of the total renewable water of some countries, and create hydrological, social, and economic interdependencies between countries (Hoekstra and Mekonnen, 2012). Transboundary water resources crossing national borders are a high-profile example. In basins like the Nile, water availability of the downstream countries (Sudan, Egypt) is highly dependent on upstream precipitation patterns and upstream water use (Drieschova et al., 2008). Transboundary river basins cover almost half of the earth's land surface, and are home to about one-third of the world's population (UN Water, 2013).

"Hydro-political dependency" in transboundary river basins is an important geopolitical issue bound up with concerns of sovereignty, and affects the power relations between riparian countries (Brochmann and Gleditsch, 2012; Giordano and Wolf, 2003; Gleick, 2014; Jägerskog and Zeitoun, 2009; Mirumachi, 2013, 2015; Wolf, 1998, 1999, 2007). An 
increase in water demand is among the main factors responsible for water scarcity in most transboundary river basins (Degefu et al., 2016). Uncontrolled land and water development in upstream regions can escalate risk of water supply uncertainty in the downstream region (Al-Faraj and Scholz, 2015; Drieschova et al., 2008; Veldkamp et al., 2017). Concerns about water availability are already considered to be one of the most important issues for international cooperation and conflict concerning shared water basins (Beck et al., 2014). Regional and global studies already show that upstream water use has a considerable impact on downstream water scarcity (Munia et al., 2016; Nepal et al., 2014; Scott et al., 2003; Veldkamp et al., 2017). When populations (or water withdrawals) grow, downstream countries eventually become more reliant on the water available from upstream parts of a basin in order to satisfy their needs.

In this study, we aim to explore one particular definition of "upstream dependency". Intuitively, one could say that upstream water dependency occurs if water from upstream is needed to avoid water scarcity. Dependency therefore involves a sharp transition between cases where water scarcity is or is not experienced depending on whether water from upstream is or is not available. Transitions between cases is a key idea in resilience thinking, which therefore provides a promising way of approaching this problem.

\section{A resilience perspective on upstream dependency}

"Resilience" of a socio-ecological system is defined as "the capacity of a system to absorb disturbance and reorganise while undergoing change so as to still retain essentially the same function, structure, identity, and feedbacks" (Walker et al., 2004, p. 01). Changes in the system are tracked in terms of "state variables", such that thresholds in those state variables are used to define the points at which change occurs in the system function, structure, identity, and feedbacks. When a threshold is crossed and changes occur, we say that the system has moved to a different "basin of attraction", that there has been a "regime shift", or a "transition between system regimes". While some studies aim to quantify resilience, we focus on identifying circumstances in which these regime shifts occur.

Understanding thresholds and regime shifts is considered critical to adaptability and transformations in transboundary basin management (Green et al., 2013). In the case of upstream dependency, we would distinguish between different system regimes depending on whether or not water scarcity occurs and whether or not dependency occurs and its implication in the prevention of scarcity. Dependency occurs in a region when there is a transition between scarcity system regimes when considering cases where water is or is not available from upstream. We therefore compare whether scarcity occurs when water availability is calculated using solely local runoff, natural discharge (sum of local runoff and upstream runoff), and actual discharge (subtracting upstream water withdrawals from natural discharge). System regimes categorised as "Scarcity" and "No scarcity" are distinguished by a change in function of the system - water becomes insufficient in some sense. For the purpose of developing our analytical framework, occurrence of scarcity is determined using commonly-used water shortage and water stress indicators (further discussed in Sect. 2.2.2). Water scarcity can also be socially induced. That is, social systems rather than climatic or hydrological factors lead to scarcity, disadvantaging groups within society and often marginalised groups (Mehta, 2013). Management actions may enable water to become sufficient and demonstrates a case where structural changes occur, and therefore also a transition between system regimes. However, as a first step to operationalise the concept of physical dependency over water, we focus on thresholds of physical scarcity, following existing studies (Brown and Matlock, 2011; Kummu et al., 2010; Porkka et al., 2012).

Transitions in system regimes in terms of dependency can occur over time, and regions can be classified according to their dependency category. Based on the role of upstream inflows and withdrawals, a region might experience: (i) no dependency if scarcity is not affected by upstream inflows, (ii) "hidden" dependency if scarcity is altered by upstream inflows but not by upstream water withdrawal, or (iii) "open" dependency if scarcity is altered after accounting for upstream water withdrawals. If a system transitions into a hidden dependency regime, the structure of the system changes - upstream withdrawals can now alter the scarcity category. The "hidden" nature of the dependency refers to the observation that a downstream part of a basin might be avoiding water scarcity only thanks to upstream inflows, and water users may not actually realise this causal factor unless those inflows are no longer available, due to increased upstream withdrawals or lower upstream runoff due to climate change or variation. The dependency becomes "open" when the role of upstream inflows becomes obvious because water scarcity does eventuate. That is, there is a transition to an open dependency regime, which can also occur due to further increases in local demand. The system may then have a loss of function (insufficient water) or change in structure (due to management actions). Examining these system regimes helps to understand possible transitions of a region, and the actions that may be needed to avoid or control transition processes, e.g. negotiating water treaties to prevent or smooth the transition to an open dependency regime. We emphasise repeatedly throughout this article that upstream withdrawals may also affect the intensity of scarcity - our focus here is specifically on transitions between regimes.

A summary of the key terms used in the analysis is given in Table 1. These definitions of upstream water dependency and dependency categories form the basis of our quantitative analytical framework. The framework is used to conduct a global analysis that quantitatively distinguishes different scarcity and dependency regimes at a transboundary sub-basin scale, i.e. parts of basins that belong to different 
Table 1. Key terminology used in the analysis and their definitions. Note: definitions in terms of water availability volumes emerge from our analysis, as described in Sect. 2 and summarised visually in Fig. 4. Our analysis method did not consider the case where actual discharge may be greater than natural discharge.

\begin{tabular}{|c|c|}
\hline Term & Definition \\
\hline Water stress & Demand-driven water scarcity, calculated as use to availability ratio \\
\hline Water shortage & Population-driven water scarcity, calculated as water availability per capita \\
\hline Local runoff & Runoff occurring internally within a region (in this paper a sub-basin). \\
\hline Upstream runoff & Runoff of the possible upstream region (in this paper a sum of runoff of upstream sub-basins) \\
\hline Natural discharge & $\begin{array}{l}\text { Total water availability before taking into account possible upstream water withdrawals, here } \\
\text { calculated as local runoff }+ \text { upstream runoff. }\end{array}$ \\
\hline Actual discharge & $\begin{array}{l}\text { Total water availability after upstream water withdrawals; calculated as natural discharge - } \\
\text { upstream withdrawals (local runoff + upstream runoff - upstream withdrawals). }\end{array}$ \\
\hline No dependency & $\begin{array}{l}\text { Upstream inflows do not influence whether or not a region experiences scarcity, i.e. if a region } \\
\text { experiences scarcity or not with only local runoff, additional water from upstream does not change } \\
\text { this situation, nor do the upstream water withdrawals. Note that the severity of scarcity may still } \\
\text { be affected by upstream inflows and water withdrawals. No dependency can be expressed as } \\
\text { local demand } \leq \text { local runoff OR local demand } \geq \text { natural discharge. }\end{array}$ \\
\hline Dependency & $\begin{array}{l}\text { Upstream inflows influence whether a region experiences scarcity or not, i.e. how water is } \\
\text { managed upstream can change the type of water management regime needed downstream. } \\
\text { Dependency can be expressed as } \\
\text { local runoff }<\text { local demand }<\text { natural discharge. } \\
\text { Two sub-types of dependency can be distinguished (as follows). }\end{array}$ \\
\hline Hidden dependency & $\begin{array}{l}\text { Scarcity category is altered by upstream inflows but not by upstream water withdrawals, i.e. local } \\
\text { runoff is not enough to meet the local demand but additional water from upstream means the } \\
\text { region experiences no scarcity instead of scarcity. Upstream withdrawals are small enough not to } \\
\text { change the scarcity status. Hidden dependency can be expressed as } \\
\text { local runoff }<\text { local demand } \leq \text { actual discharge. }\end{array}$ \\
\hline Open dependency & $\begin{array}{l}\text { Scarcity category is altered after accounting for upstream water withdrawals, i.e. while upstream } \\
\text { inflows in the hidden dependency allowed the region to avoid scarcity, upstream withdrawals } \\
\text { now mean that the SBA does experience scarcity and more intense water management regimes } \\
\text { are needed downstream. Open dependency can be expressed as } \\
\text { actual discharge }<\text { local demand }<\text { natural discharge. }\end{array}$ \\
\hline
\end{tabular}

countries. Figure 1 summarises the key ideas of this paper. Specifically, we aim to answer the following research questions:

- What is the current dependency category of each subbasin?

- How do climate, upstream withdrawals, and local demand influence the dependency category? What transitions to other dependency categories are possible that should perhaps be considered in planning for the future?

- How do regime shifts involving hidden and open dependencies relate to negotiations in transboundary basins?

Our analysis is based on modelled water availability and water use data (Sect. 2.1). Our Methods section builds up our analytical framework, defining sub-basins and calculating the different types of water availability (Sect. 2.2.1), interpreting upstream dependency in terms of water scarcity (Sect. 2.2.2), and unpacking determinants of dependency categories and transitions between them (Sect. 2.2.3). Applying this method to global transboundary basins, our results describe dependency categories in the year 2010 and how they affect the problems faced by the sub-basins (Sect. 3). We then describe how the transitions between scarcity and dependency system regimes affect negotiation with upstream sub-basins to avoid the need to cope with scarcity (Sect. 4.1). We conclude with a discussion of opportunities for further work building on and improving this method and dependency typology (Sects. 4.2 and 4.3).

\section{Data and methods}

To operationalise our definition of upstream water dependency, we used the global hydrological model PCRaster Global Water Balance (PCR-GLOBWB) to simulate water use and water availability at grid cell resolution (30 arcmin or roughly $50 \mathrm{~km}$ by $50 \mathrm{~km}$ at the equator). A basin-country mesh was used to subdivide the transboundary basins into sub-basin areas (SBAs). We then examine differences in the scarcity of available water of the different types in order to 
Table 2. Datasets used in the study together with their source.

\begin{tabular}{|c|c|c|c|}
\hline Data & Year & Source & Description \\
\hline Drainage direction & - & Döll (2002) & Global grid with 30 arcmin resolution \\
\hline Runoff & $1981-2010$ & $\begin{array}{l}\text { Wada et al. (2011a, 2013), } \\
\text { Wanders et al. (2018) }\end{array}$ & Monthly data at global grid with 30 arcmin resolution \\
\hline Irrigation water withdrawal & $1981-2010$ & $\begin{array}{l}\text { Wada et al. (2011a, 2013), } \\
\text { Wanders et al. (2018) }\end{array}$ & Monthly data at global grid with 30 arcmin resolution \\
\hline Industrial water withdrawal & $1981-2010$ & $\begin{array}{l}\text { Wada et al. (2011a, 2013, } \\
\text { Wanders et al. (2018) }\end{array}$ & Monthly data at global grid with 30 arcmin resolution \\
\hline Domestic water withdrawal & $1981-2010$ & $\begin{array}{l}\text { Wada et al. (2011a, 2013), } \\
\text { Wanders et al. (2018) }\end{array}$ & Monthly data at global grid with 30 arcmin resolution \\
\hline Population density & 1981-2010 & Klein Goldewijk et al. (2010) & HYDE dataset \\
\hline
\end{tabular}

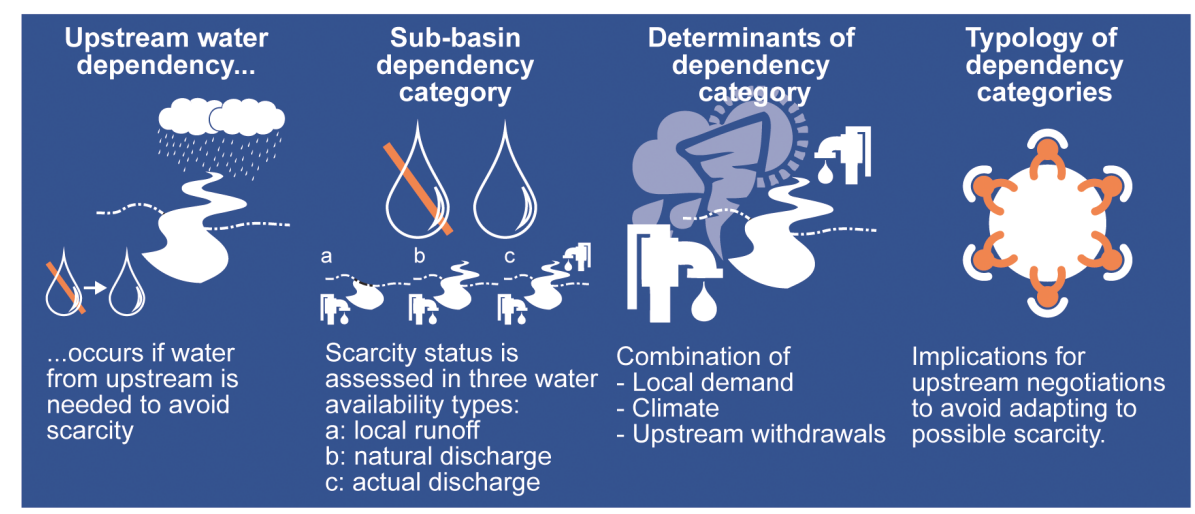

Figure 1. Key ideas of this study: our definition of dependency and themes addressed by our research questions.

provide a first explanation of why dependency occurs. Below we present in more detail the data, methods, and analytical framework used for the assessment.

\subsection{Data}

The data used for the study are summarised in Table 2. Runoff and water withdrawals (WWs) were calculated using the PCR-GLOBWB 30 arcmin model (Wada et al., 2011a, 2013; Wanders et al., 2018). PCR-GLOBWB is a conceptual, process-based water balance model. In brief, it simulates for each grid cell and for each time step (daily) the water balance in two vertically stacked soil layers and an underlying ground water layer, as well as the water exchange between the layers and between the top layer and the atmosphere (rainfall, evaporation, and snowmelt) (Wada et al., 2013). Discharge estimates from the model are extensively validated against observations from the Global Runoff Data Centre (GRDC) in existing publications by Wada et al. (2013, 2014). The return flows from industrial and domestic sectors have been taken into account in PCR-GLOBWB and the recycling ratios for industrial and domestic sectors have been estimated (roughly $40-80 \%$ ) at a country level and validated based on Wada et al. (2011a, 2014).
Total WW was calculated for each SBA as the sum of three water use sectors: irrigation, domestic, and industrial. The water use data for these sectors were obtained from the same model as the discharge simulations (Wada et al., 2011a, 2013; Wanders et al., 2018). Water use estimates have also been previously validated against reported country data, notably FAO AQUASTAT, by Wada et al. (2011a). In this analysis, water withdrawals refer to the total amount of water withdrawn, but not necessarily consumed, by each sector, much of which is returned to the water environment where it may be available to be withdrawn again. However, estimation of return flows is uncertain and they may not necessarily be available to downstream users, for example because of pollution, timing of the flows, or infiltration to groundwater (Wada et al., 2011a, b). Thus, the return flows were not subtracted from withdrawals in this analysis.

To provide an indication of need for water (rather than withdrawals), population density information was obtained from the HYDE 3.2 dataset for each year from 1981 to 2010 (Klein Goldewijk et al., 2010). The data were first aggregated from 5 to 30 arcmin resolution and then for each SBA for every year over the 30-year period.

The 30 arcmin raster dataset DDM30 (Döll, 2002) described drainage direction for both surface flow routing 
in PCR-GLOBWB and definition of upstream-downstream links.

Country boundaries were first rasterised from Natural Earth admin 0 boundaries (Natural Earth, 2017). Border cells were then manually assigned to countries to provide meaningful hydrological relationships. In general, single cell SBAs were avoided. Cells where country borders follow a river were treated as separate "shared" zones. What we refer to as a "country" raster therefore includes both countries and shared zones.

\subsection{Methods}

\subsubsection{Sub-basin definition and calculation of water availability}

To explain the methods and analytical framework used for the global assessment, we use the Oder - a river in central Europe - as an example case study (Fig. 2). The Oder is a transboundary river that rises in the Czech Republic and flows through western Poland, later forming the border between Poland and Germany. We chose the Oder river basin as an example case study because (i) it has non-trivial but sufficiently easy hydrological connections for illustrative purposes; (ii) it includes upstream, middle stream, and downstream SBAs; and (iii) the water stress levels and downstream dependencies illustrate well the use of our analytical framework.

SBAs were defined by breaking up the drainage direction map where it flows across country (and shared zone) boundaries, effectively yielding a mesh of river basin and country boundaries. Upstream-downstream relationships between these SBAs were defined by the flow direction dataset. The construction of the country raster (see Sect. 2.1) ensured that the SBAs provide a meaningful representation of the hydrological system. A country can have multiple SBAs in order to capture different flow paths. In general, the drainage direction raster captures major tributaries even if finer details are missing. In the case of the Oder basin, Fig. 2 presents the four identified SBAs $\left(_{\text {OdSBA }}\right.$, OdSBAPO-A OdSBAPO-B, OdSBA $_{\mathrm{GE}}$ ) and the direction of flow between these SBAs. The Czech Republic (OdSBA $\mathrm{CZ}$ ) has been identified as the most upstream, part of Poland (OdSBAPO-A) and Germany $\left(\mathrm{OdSBA}_{\mathrm{GE}}\right.$, where the river forms the border) as middle stream, and part of Poland (OdSBAPO-B) as the most downstream (Fig. 2).

Three types of average annual water availability (for 1981-2010) were calculated in each of these SBAs, corresponding to local water (local runoff), total inflows including upstream areas (natural discharge), and total inflows after upstream WWs (actual discharge) (see detailed definitions in Table 1). We approximate discharge as the sum of local runoff in local and upstream SBAs, such that there is an arithmetic relationship between the two. This provides an easy-to-follow abstraction of the problem that emphasises upstream-downstream relationships while ignoring issues of land use change, timing of flows, and conveyance losses. WW for each SBA was calculated separately (referred to as WW.local) by summing up the three water use sectors (industrial, domestic and agriculture) for the year 2010 and aggregating to the SBA scale. Local runoff for each SBA (avail.local) was given by its average runoff. Natural discharge (avail.natural) for each SBA was calculated by summing together the local runoff of the SBA and all its upstream SBAs.

Actual discharge (avail.actual) was calculated from the SBA WWs and total water availability. We identified the entire upstream area for each SBA based on the upstreamdownstream hierarchy, i.e. in cases when an SBA has more than one upstream SBA, the total upstream WWs are summed (WW.upstream). The drainage network used here to identify upstream-downstream relationships has a clear hierarchical relation, with no distributaries, so water only flows to one immediately downstream SBA and there is no risk of double counting. These WWs were then subtracted from natural discharge for the corresponding year, i.e. avail.actual $=$ avail.natural $-W W$.upstream . In some cases, avail.actual in excess of avail.local is considered to be fossil ground water or other available water that is not included in the calculation. In these cases, we set avail.actual to be equal to avail.local for that SBA.

\subsubsection{Interpretation of upstream dependency in terms of water scarcity}

Looking at the average availability of water (1981-2010) for the SBAs of the Oder basin provides an illustration of the concept of upstream dependency (Fig. 2). The headwater SBA (OdSBA ${ }_{C Z}$ ) obviously has no upstream dependency; the three types of water availability are the same. But in the case of SBAs OdSBAPO-A, OdSBAPO-B, and OdSBA ${ }_{\mathrm{GE}}$, upstream water availability and withdrawals influence water availability. These are the SBAs we are most interested in.

Dependency on upstream water can be assessed by comparing an SBA's scarcity category across the different water availability types (i.e. local runoff, natural discharge, actual discharge - see definitions in Table 1). We calculated scarcity using water stress and water shortage indices. Water stress refers to impacts from high use of water, while water shortage refers to impacts from insufficient water availability per person (Falkenmark et al., 2007; Kummu et al., 2016).

The stress indicator was calculated as WW.local/avail and the shortage indicator is calculated as avail/population.local. The stress indicator includes environmental flow requirements (EFRs), assuming 30\% of the water is needed to satisfy the EFRs (Falkenmark et al., 2007). To determine whether water stress or shortage occurs, we respectively used the thresholds of 0.2 and $1000 \mathrm{~m}^{3} \mathrm{cap}^{-1} \mathrm{yr}^{-1}$, as defined by Falkenmark et al. (2007) and used by other research too (Liu et al., 2017). Crossing these thresholds leads to impacts from insufficient water availability per person, potentially limit- 


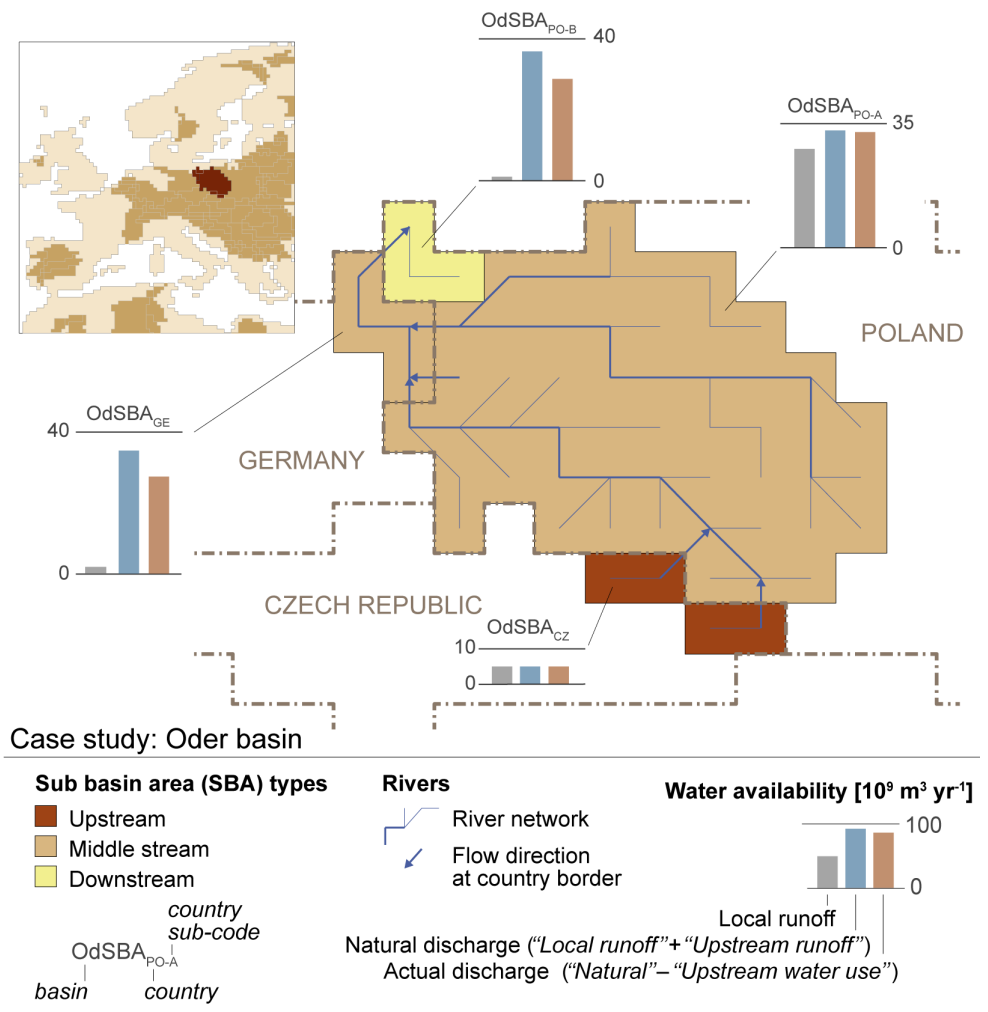

Figure 2. Upstream-downstream relationship between sub-basin areas (SBAs) in the Oder basin and average simulated annual water availability for 1981-2010. Drainage network and sub-basin division are based on DDM30 (Döll, 2002) and country borders (Natural Earth, 2017) with additional manual assignment of border cells.

ing economic development and human health and well-being (Falkenmark et al., 2007). Using annual values may mask water scarcity during the dry season. Falkenmark's per capita water availability as a measure of water scarcity has limitations as an indicator. Nevertheless, both stress and shortage are useful indicators of the more general concept of scarcity. Shortage, measured by per capita water availability, captures an important intuition that sufficiency of water availability depends on population. Even though the thresholds are arbitrary, using both indicators provides a useful balance to understand the development of water scarcity (Kummu et al., 2016), as well as illustrating the generality of the analysis framework. The use of these thresholds is in line with existing studies and while interpretation of the results is limited by the simplicity of the indicators, they provide a first step in understanding upstream dependency.

Annual stress and shortage were calculated using WWs and population for 2010 with (1) local runoff, (2) natural discharge, and (3) actual discharge. Equations for water stress are

$$
\begin{aligned}
& \frac{\text { WW.local }}{\text { avail.local }} \\
& \frac{\text { WW.local }}{\text { avail.natural }}
\end{aligned}
$$

$\frac{W W . l o c a l}{\text { avail.natural }-W W . \text { upstream }}$.

Equations for water shortage are

$$
\begin{aligned}
& \frac{\text { avail.local }}{\text { population.local }} ; \\
& \frac{\text { avail.natural }}{\text { population.local }} ; \\
& \frac{\text { avail.natural }-W W . u p s t r e a m}{\text { population.local }} .
\end{aligned}
$$

The water scarcity status was categorised as "No scarcity" (N) and "Scarcity" (S) using average annual water availability from 1981 to 2010 . The 30 -year period was used to capture the current hydro-climatic characteristics. Figure $3 \mathrm{a}$ represents scarcity for the three water availability types for the Oder basin under average conditions, shown within the Falkenmark matrix (Falkenmark et al., 2007; Kummu et al., 2016) which shows stress and shortage together. Archetypes in the Falkenmark matrix describe the water scarcity status (corresponding to position on the plot) and where both shortage and stress occur, according to which occurs first (Kummu et al., 2016). Figure 4 defines the four possible different dependency categories in terms of the scarcity an SBA can face, as illustrated by the discussion below. 


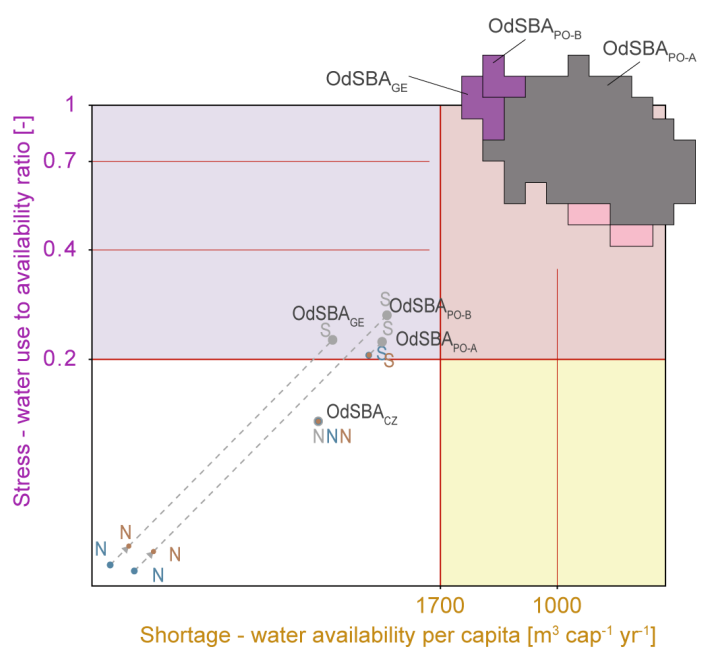

(a) Scarcity matrix for Oder sub-basin areas (SBAs)

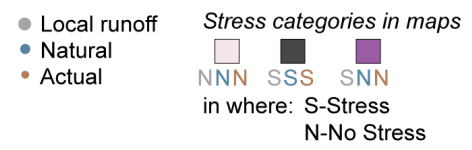

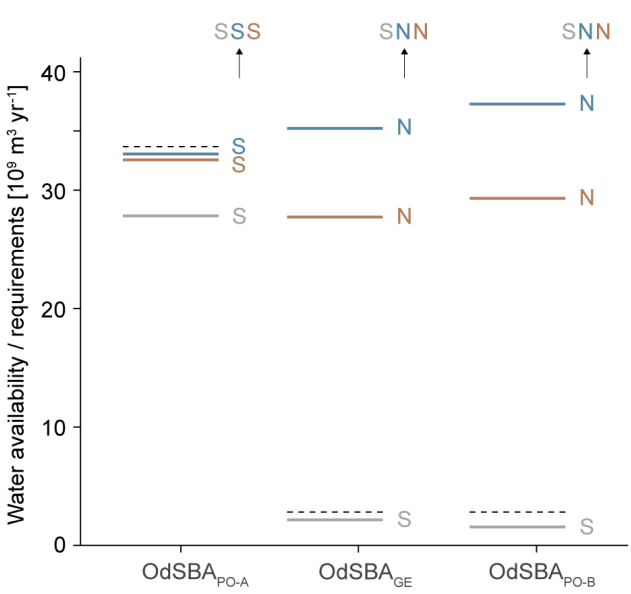

(b) Water availailability and requirements in Oder sub-basin areas (SBAs)

$$
\begin{aligned}
& \text { Water availability } \\
& - \text { Natural ("Local runoff" + "Upstream runoff") } \\
& - \text { Actual ("Natural"-"Upstream water use") } \\
& - \text { Local runoff } \\
& \text { - - - Water availability required to achieve stress }=0.2 \text {, } \\
& \quad \text { given local water withdrawals in year } 2010
\end{aligned}
$$

Figure 3. Scarcity and dependency category for the Oder sub-basin areas (SBAs) under annual average conditions. The Falkenmark matrix (a) and plot of water availability required to avoid stress (b) show changes in stress and shortage under different types of water availability (see definitions in Table 1). The inset map represents the Oder SBAs corresponding dependency categories. Scarcity and dependency categories for each SBA for the year 2010 were calculated using a water stress threshold value of 0.2 and water shortage threshold value of $1000 \mathrm{~m}^{3} \mathrm{cap}^{-1} \mathrm{yr}^{-1}$.

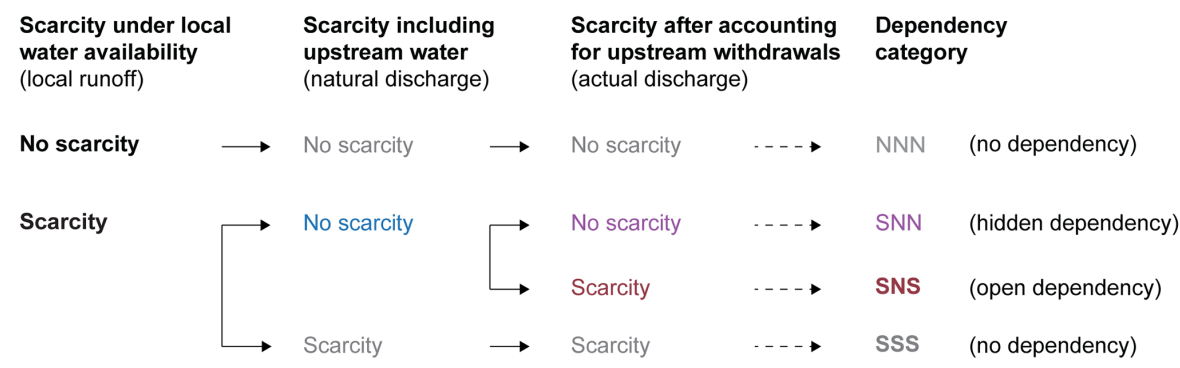

Scarcity and dependency category

$\begin{array}{ll}\text { No dependency } & \mathbf{N}=\text { No Scarcity } \\ \text { Dependency } & \mathbf{S}=\text { Scarcity } \\ \text { Hidden dependency } & \\ \text { Open dependency } & \end{array}$

Figure 4. Definition of potential upstream water dependency categories. Dependency categories are obtained by summarising three letter codes representing the scarcity category using local runoff, natural discharge, and actual discharge respectively (see definitions in Table 1).

None of the SBAs have any shortage as the per capita water availability has never dropped below $1000 \mathrm{~m}^{3} \mathrm{cap}^{-1} \mathrm{yr}^{-1}$.

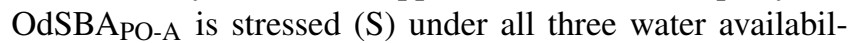
ity types, and OdSBA $\mathrm{CZ}$ is not stressed $(\mathrm{N})$. OdSBA $\mathrm{OE}_{\mathrm{GE}}$ and OdSBAPO-B would both be stressed (S) only if they were restricted to their local runoff (Fig. 3a). After accounting for inflows from upstream (natural discharge), the stress level decreased from 0.25 to $0.01(\mathrm{~N})$ for OdSBA $\mathrm{GE}$ and from 0.35 to $0.01(\mathrm{~N})$ for OdSBAPO-B (Fig. 3a). This change in stress category means that both of these SBAs are dependent on upstream water to avoid stress. We further see that upstream WW increases the stress level relative to natural conditions (to 0.02 for both; Fig. 3a and c), but the threshold for stress was not crossed. The stress level changed without changing the stress category, such that the category of the dependency was not affected; we have a "hidden" rather than "open" dependency (definitions in Table 1). In the case of OdSBAPO-A, local runoff is not sufficient to meet needs and that upstream 
water availability and WWs do not influence the scarcity category of this SBA. This SBA is under the same scarcity conditions regardless of upstream influence (Fig. 3a and b), and it is thus categorised as "No dependency", though the intensity of scarcity is still affected by upstream WW. The dependency category of an SBA can then be summarised using three letter codes representing the scarcity category using local runoff, natural discharge, and actual discharge respectively: OdSBA ${ }_{\mathrm{GE}}$ and OdSBAPO-B are SNN, OdSBAPO-A is SSS, and OdSBA ${ }_{C Z}$ is NNN (Fig. 3a).

\subsubsection{Determinants of dependency category and possible transitions in them}

In order to evaluate possible responses to dependency, we need to understand what determines a dependency category and what can be done to achieve or to avoid change. Annual water availability can be thought of as a constraint on the environment in which a society operates. Society is able to influence that constraint, for example by building reservoirs (Veldkamp et al., 2017) - captured to some extent by the model. However, for a given hydro-climate and state of development, it is useful to think of the current water availability regime as an integral, defining characteristic of a system regime. As population and WW increase in a region, the occurrence of shortage, stress, and upstream dependency is determined by the volumes of the three types of water availability. A region will face scarcity or dependency as a result of

- insufficient local runoff (avail.local);

- insufficient discharge, from local runoff and possible upstream inflows (avail.natural);

- insufficient discharge after upstream WW (i.e. water withdrawals) (avail.actual).

From a resilience perspective, these volumes of water can be thought of as thresholds, where an SBA would be under the "No scarcity" category when its average local runoff (avail.local) is sufficient to meet the water demand in a given year and "Scarcity" category when its average natural discharge (avail.natural) is insufficient in relation to its water demand. In this study, "demand" is used as a high-level umbrella term covering both actual withdrawals (for the stress indicator) and need for water (population, for the shortage indicator).

Figure 5 shows the ordering of possible thresholds for an SBA based on water availability, and how the shortage and stress categories vary as demand changes. To allow comparison, water availability, population, and withdrawal are all expressed as percentages respectively of avail.natural, carrying capacity (avail.natural/1000), and sustainable yield (avail.natural $\times 0.2$ ). The current status of $\mathrm{OdSBA}_{\mathrm{GE}}$ and OdSBAPO-B is shown in the figure. Currently OdSBA $_{\mathrm{GE}}$ and OdSBAPO-B are in the "SNN" category for stress and "NNN"
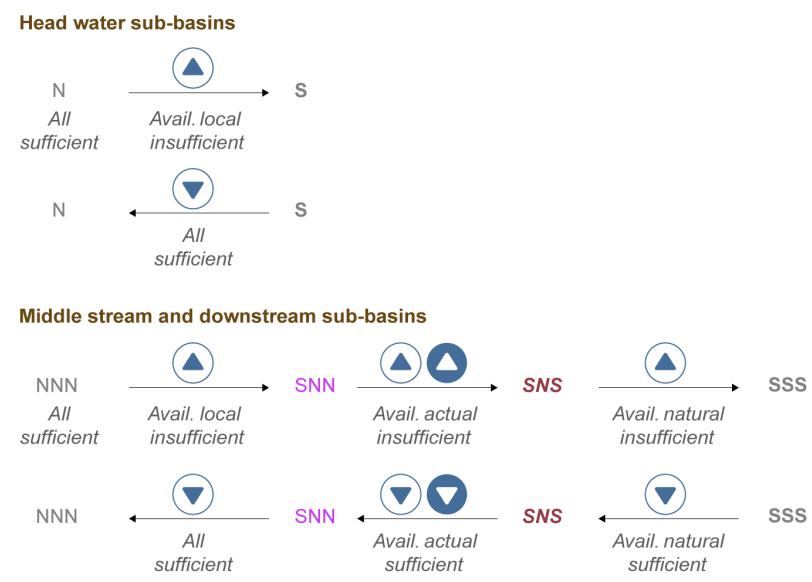

(a) Typology of possible transitions in dependency category

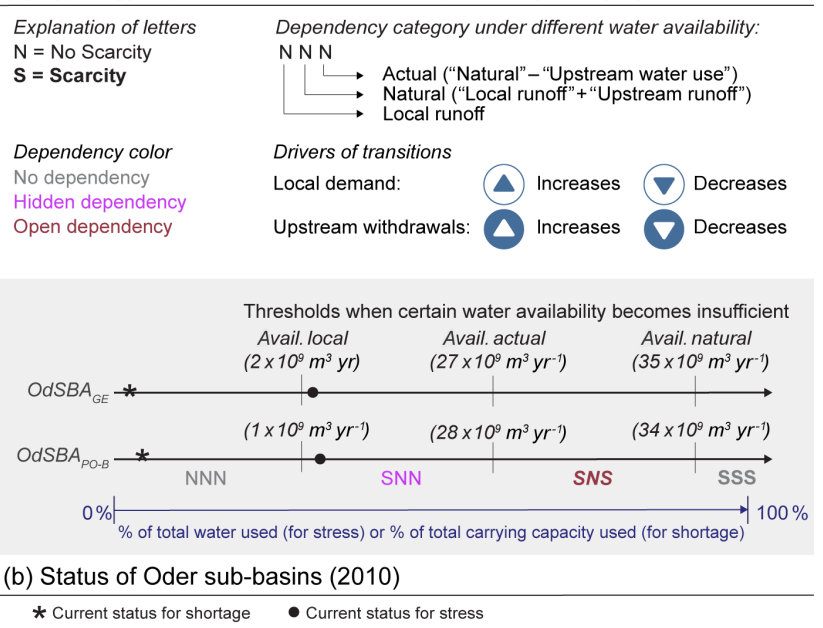

Figure 5. Typology of possible transitions in dependency category, as local water demand or upstream water withdrawals (WW) increase or decrease (a). Upstream WWs decrease the downstream water availability, while local water demand increases the pressure on available resources. The current (2010) status of $\operatorname{OdSBA}_{\mathrm{GE}}$ and OdSBAPO-B (for both stress and shortage) is shown in the transition map (b). See definitions of terminology in Table 1.

category for shortage (Fig. 3). They have hidden dependencies (avoiding stress) as the average year inflows after upstream WW are sufficient to meet water demand. If the water demand in these SBAs were to increase to a level where the average year inflows after upstream WW (avail.actual) would not be enough to meet demand, the SBA would next transition from SNN to the SNS category. Thus, with the increase in demand, the dependency category (e.g. "SNS") would change based on the thresholds it crosses and ultimately the basin would become SSS, indicating that an SBA would be under scarcity under each type of water availability considered. The same thing would happen with shortage as the population increases (Fig. 5). Over time, this change in dependency category could go forward and backward as wa- 
(a) Sub-basins under different dependency category in case of water stress

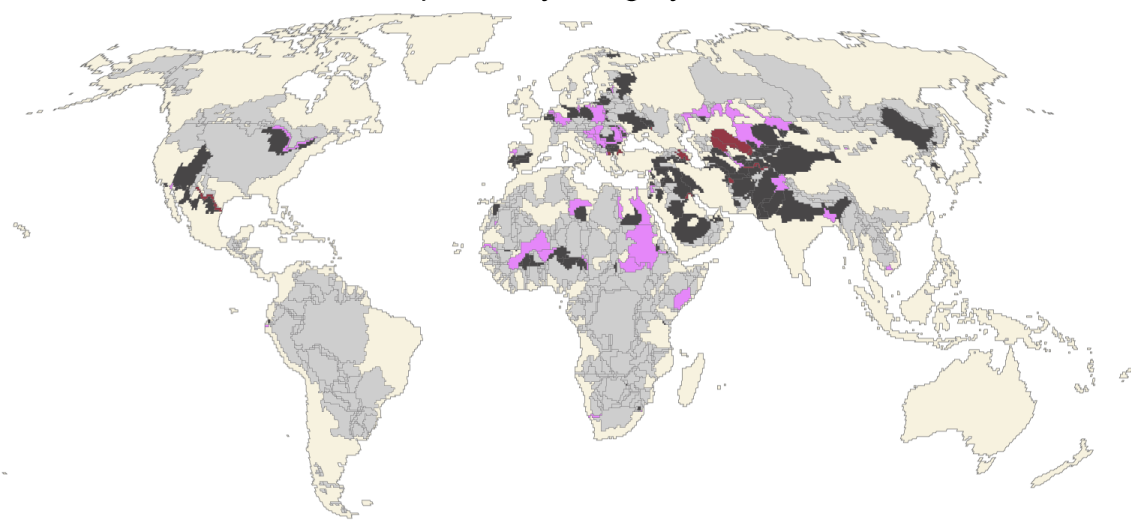

(b) Sub-basins under different dependency category in case of water shortage

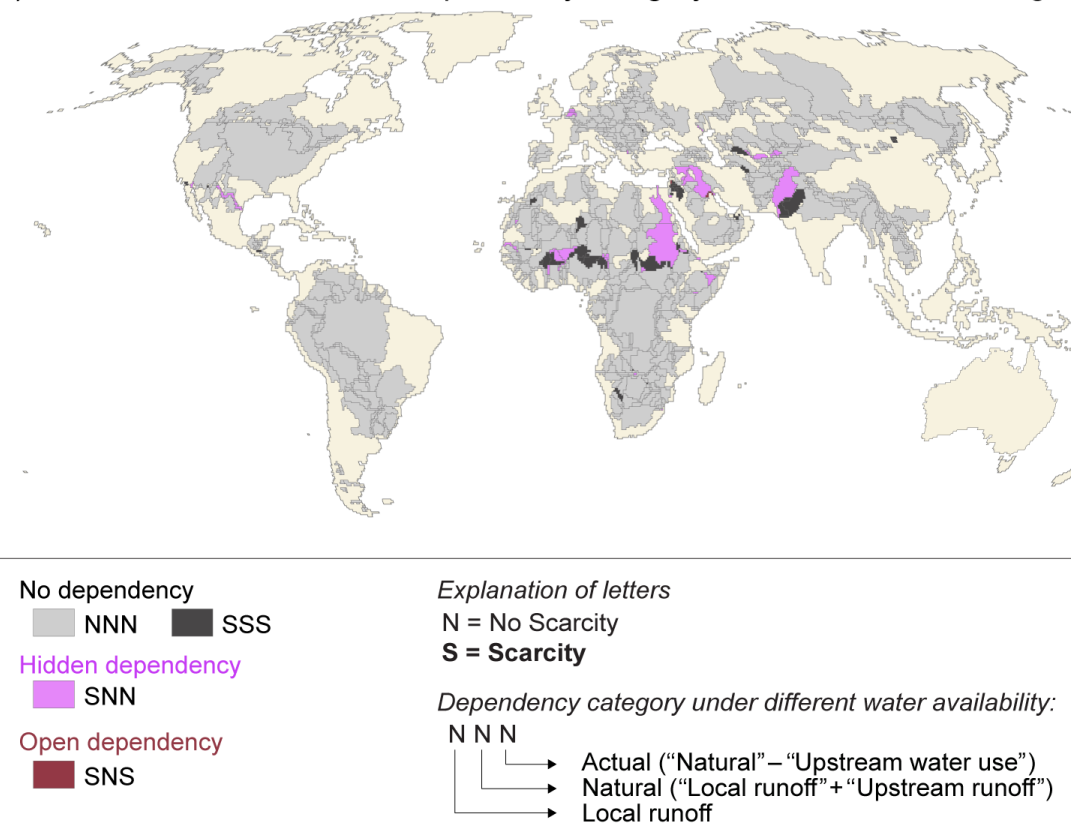

Figure 6. Dependency categories for each sub-basin area (SBA) for the year 2010 using (a) a water stress threshold value of 0.2 and (b) a water shortage threshold value of $1000 \mathrm{~m}^{3} \mathrm{yr}^{-1} \mathrm{cap}^{-1}$. See definitions of dependency categories in Fig. 4 and definitions of key terminology in Table 1.

ter demand of the SBA increases or decreases. This order of thresholds determines the transition in dependency category for $\operatorname{OdSBA}_{\mathrm{GE}}$ and OdSBAPO-B as local demand increases or decreases.

So far, we have conceptualised change in dependency category in the context of a fixed set of water availability thresholds, obtained directly from estimated water availability volumes. The order of thresholds determines the transition in dependency category as local demand increases or decreases. In fact, even if upstream WW changes the values of the thresholds, their order will remain the same. These scarcity thresholds are naturally ordered because local water necessarily becomes insufficient before upstream water availability types: local $\leq$ actual $\leq$ natural. We do, however, dis- tinguish between headwaters vs. middle stream and downstream SBAs.

Headwaters are the simplest case. Given they are the most upstream SBAs, they rely solely on local runoff, Increases in an SBA's demand cause a transition from "No scarcity" to the "Scarcity" category. Decrease in demand would have the opposite effect (Fig. 5).

In the case of middle stream and downstream SBAs, transition occurs between four scarcity categories, which are connected by a simple map of transitions: NNN-SNN-SNS-SSS. Transition in the scarcity category depends on both local demand and upstream WW. The experience of dependency in the Oder basin is therefore generally applicable to all middle and downstream SBAs. As the local demand increases, the 
Table 3. Number of SBAs under different dependency categories in the year 2010.

\begin{tabular}{|c|c|c|c|c|c|}
\hline & \multirow{2}{*}{$\begin{array}{l}\text { Dependency } \\
\text { category }\end{array}$} & \multicolumn{2}{|c|}{ Stress } & \multicolumn{2}{|c|}{ Shortage } \\
\hline & & $\begin{array}{l}\text { No. of } \\
\text { sub-basins }\end{array}$ & $\begin{array}{l}\text { Population } \\
\left(\times 10^{6}\right)\end{array}$ & $\begin{array}{l}\text { No. of } \\
\text { sub-basins }\end{array}$ & $\begin{array}{l}\text { Population } \\
\left(\times 10^{6}\right)\end{array}$ \\
\hline \multirow[t]{2}{*}{ No upstream dependency } & $\mathrm{NNN}$ & $688(78 \%)$ & $1231(44 \%)$ & $799(90 \%)$ & $2312(83 \%)$ \\
\hline & SSS & $136(15 \%)$ & $1150(41 \%)$ & $50(6 \%)$ & $172(6 \%)$ \\
\hline Hidden dependency & SNN & $52(6 \%)$ & $386(14 \%)$ & $35(4 \%)$ & $306(11 \%)$ \\
\hline Open dependency & SNS & $10(1 \%)$ & $25(0.9 \%)$ & $2(0.2 \%)$ & $2(0.7 \%)$ \\
\hline Total & & 886 & 2792 & 886 & 2792 \\
\hline
\end{tabular}

SBA moves from NNN to SNN, exposing it to a "hidden dependency" as local runoff become insufficient, but the SBA still receives sufficient upstream inflows to meet the local demand. The next transition between SNN to SNS is dependent on both local demand and upstream WW until local demand increases to the level where all available water become insufficient - the SBA becomes SSS. The decrease in local demand and upstream WW will have the opposite effect.

Thus SBA crosses thresholds which not only change the scarcity category but also change the dependency category, considered in this study as transitions between different "system regimes". Note that we focus on the effect of increasing or decreasing local demand and upstream WW, leaving changes in water availability to future work.

\section{Results: global analysis of dependency categories}

The analysis was applied to 246 international transboundary basins to understand the dependency category of these basins and possible future transitions, using WW and population data from 2010.

The 246 transboundary basins were divided into 886 SBAs based on country borders (as well as shared zones along those borders). As shown in Table 3, in the case of stress, most SBAs had no dependency in 2010 (93\%, 824 SBAs), while 52 SBAs have a hidden dependency - water available from upstream lifts the SBA from scarcity and upstream WWs do not change the scarcity category (though they may still intensify scarcity where it occurs, see the Discussion section). In total $10(1 \%)$ SBAs are identified where the dependency was open, meaning that upstream water withdrawals change the downstream stress category (Table 3 ). In the case of shortage, 35 SBAs were under hidden dependency and only 2 under open dependency. Upstream WWs thus only rarely play a role in causing low water availability per capita.

"No dependency" is observed in $93 \%$ of cases for stress and $96 \%$ of cases for shortage (Table 3). It is worth noting that scarcity can still be experienced without a dependency - it simply means that current upstream inflows (and WWs) do not influence whether scarcity occurs. For example, in the case of water stress, $41 \%$ of the population living in SBAs under "No dependency" are under stressed conditions (Table 3). Further, even if an SBA in question is under no dependency category, upstream WW might still intensify the possible scarcity. In this category, there is not currently a problem with relationships with upstream SBAs, but to plan ahead, we need to understand how the situation could evolve, as is discussed in Sect. 4.1.

"Hidden dependency" is observed for both stress and shortage mostly in Africa, some parts of Southeast Asia, and Europe (Fig. 6a and b). Hidden dependency means that maintaining good relationships and assessing water use and potential changes with upstream basins are important to avoid scarcity. A number of SBAs in which currently no scarcity is observed (Fig. 6) are actually subject to upstream dependency. If inflows were to decrease sufficiently due to increased upstream WWs, scarcity could occur. In these SBAs, this has not yet happened, though upstream WWs may be influencing the intensity of scarcity and the level of development (population or use) at which thresholds occurs. Therefore, understanding of how the situation can evolve is needed to know how to manage the relationship with upstream water users.

"Open dependency" occurred notably in central Asia and some parts of North America for stress and for shortage, only in areas categorised as shared zones as part of the Jordan basin (Israel, Syria, and Lebanon) and the intermittent Wadi Al-Batin (forming the border between Kuwait and Iraq) (Fig. 6a and b). Open dependency indicates that scarcity occurs and could be attributed to upstream water use, such that there is a potential for tension with upstream water users over water allocation as things currently stand. But while there would be no scarcity if it were not for upstream WWs, reducing local water needs or WWs could also avoid shortage or stress. As a result, avoiding scarcity in these SBAs requires cooperation rather than uncoordinated competition between the upstream and the downstream regions. Such a situation is already evident in the case of central Asia (Dukhovny, 2014). However, understanding of the evolution of the situation may show that small decreases in local or upstream WWs may not be sufficient to avoid scarcity or dependency. It may be nec- 
essary to find a means to reduce needs or adapt to impacts from high water use.

\section{Discussion}

In this analysis, transboundary water dependency was examined based on the concept that an SBA is dependent on upstream inflows if it requires those inflows to avoid water scarcity (e.g. stress, shortage as used here) and associated impacts. We proposed that regime shifts discussed in the resilience literature provide a useful way of thinking about this problem, and we provide a first exploration of how this concept can be analysed.

We aimed to address three research questions. Firstly, we identified the current dependency category of each SBA. Examining occurrence of scarcity with different types of water availability allows for the classification of ways in which upstream and downstream SBAs are dependent on each other (Sects. 2.2.2 and 3). To answer the second question, we further developed the analytical framework by explaining how climate, upstream withdrawals, and local demand influence the dependency categories (Sect. 2.2.3). This yields a sequence of transitions between system regimes that describe what future changes in scarcity and dependency are possible. This leads to our third research question: how does this relate to water management and negotiations in transboundary basins?

\subsection{What are the implications for mitigation and prevention of scarcity?}

The literature on resilience and complex adaptive systems emphasises that it is difficult to predict what will happen in the future, but we can identify what are the transitions that might occur to prepare ourselves such that the system either avoids or manages those transitions. According to our framework, the starting point is a system regime with low water demand, easily satisfied by local runoff (NNN). There is no need to use upstream inflows, such that upstream withdrawals have no effect on local water scarcity. The need to engage with upstream water users begins with an increase in local water demand, transitioning to a system regime where scarcity depends on upstream withdrawals (SNN). It is in the interest of both downstream and upstream users to avoid transitioning to an open dependency (SNS), which could happen because of either increases in local demand or upstream WW (as well as changes in climate). Despite the invisible consequences of a transition to SNN, it would be worthwhile to expose the hidden dependency. Negotiation to reduce WWs may fix an open dependency, but there is also another possible outcome. If local water demand continues to increase, the dependence on upstream disappears again. Very high water demand cannot be met even with upstream inflows (SSS), such that upstream withdrawals can no longer solely cause scarcity, even if they contribute to its severity. In this system regime, negotiation with upstream regions is not sufficient to avoid scarcity, so it may be more worthwhile to look for other solutions, such as those within the political economy (Allan, 2002).

Understanding these transitions provides a basic level of guidance for a region. In a no dependency system regime (e.g. most SBAs analysed), efforts can be made to keep water demand at low enough levels to be self-sufficient. If water demand is expected to increase, monitoring is useful to avoid being surprised by the breaking of a hidden dependency. While our analysis shows relatively few open or hidden dependencies in 2010, population growth and associated water demand means that the need for water scarcityrelated negotiation in transboundary basins could become a much greater issue in the future. It is specifically the emergence of dependencies that introduces the need for negotiation. Treaties have an indirect effect on physical upstream water dependency by limiting or coordinating development of water resources locally and upstream. Treaty design can be innovated to include functions that improve the stability of the dependency and hence prevent scarcity from occurring. If decision makers cannot avoid a transition to scarcity (i.e. an open dependency), perhaps due to factors outside their control, then coordination can at least facilitate adaptation to cope with physical water scarcity. There are regions where physical water scarcity is to some extent expected - development is limited by water availability, such that fully utilising other resources (e.g. land) requires more water than is available. In addition, it should be pointed out that negotiation for rights to upstream inflows is only one strategy among many to try to meet water demand. In such cases, treaties can focus on mitigating the severity of impacts of scarcity.

Downstream areas with increasing water demand should be mindful that, in a way, they are "choosing" to have to deal with dependencies and potential scarcity. If upstream withdrawals are stable, it can be argued that any conflict is effectively of their own making. Scarcity and dependency only emerge as problems when local demand crosses a threshold. This gives the impression that it is the local user that is responsible for the new problem, even though it may simply be that they are late to the game. On the other hand, if upstream withdrawals later increase, downstream regions might argue that they would not need to deal with scarcity, were it not for upstream actions. These interpretations of responsibility rely on the idea of precedence. The precedence paradigm is visible in prior appropriations regimes in the USA, while negotiated allocations are arguably implemented by water markets in Australia and elsewhere (Grafton et al., 2011). Even in a negotiated approach, however, existing water needs and WWs are often taken into account, including at an international level - hybrid approaches are common. The UN Watercourses Convention of 1997 also refers to the no harm principle (article 7), which works in tandem with consideration as to whether a given water use is reasonable and equi- 
table (UN Watercourses Convention, 2018). These examples illustrate the close connection between water allocation and different views about responsibility for transitions.

\subsection{Relation to existing work}

Our work distinguishes between dependency and scarcity and recognises that dependency is primarily about potential for future scarcity, which transboundary cooperation aims to mitigate. To judge the importance of transboundary cooperation, it is more important to look at areas under no scarcity which are dependent on upstream inflows. The "open dependency" category (SNS) and SSS only include cases where institutional arrangements have failed to prevent scarcity from occurring. Our work, however, highlights that negotiation to avoid needing to cope with scarcity is only part of the issue. As demand increases, negotiation among riparian countries will eventually turn to discussion of intensity and frequency of scarcity, and the level of demand at which it occurs. Other existing work also distinguishes different types of rivers and basins to help understand why some riparian countries on international rivers have been able to successfully negotiate treaties and others have not - taking into account, for example, size of population, GDP, upstreamdownstream relationship, and asymmetries in economic and political power among riparian states (Delbourg and Strobl, 2012; Song and Whittington, 2004; Wolf et al., 2003). Increasing water scarcity has been identified as a risk factor, but has not previously been systematically explored in terms of upstream dependency. Our dependency category typology complements this existing work, and relations to other typologies could be explored in the future.

One of the main advantages of our analytical framework, compared to existing knowledge, is that it highlights the possible "hidden" dependency of upstream water, which has not been assessed in these terms before. Previous studies on transboundary river basins identified clear evidence of the impacts of upstream water use to downstream water availability and water scarcity level (Al-Faraj and Scholz, 2015; Munia et al., 2016; Nepal et al., 2014; Veldkamp et al., 2017). It has already been found that about $0.95-1.44$ billion transboundary people are under stress because of local water use, while upstream WWs increased the stress level by at least 1 percentage-point for 30-65 SBAs, affecting 0.29-1.13 billion people (Munia et al., 2016). Our analysis provides a different view of the issue by revealing that 386 million people (14\% of the total transboundary population) are dependent on upstream water to avoid possible stress because of their own water demand and 306 million people (11\% of the total transboundary population) are dependent on upstream water to avoid possible shortage (Table 3). Along with previous work, including a broader discussion of hydro-political dependency (Brochmann et al., 2012; Giordano and Wolf, 2003; Gleick, 2014; Jägerskog and Zeitoun, 2009; Mirumachi, 2013, 2015; Wolf, 1998, 1999, 2007), our analysis highlights the importance of local demand in causing scarcity and dependency. If local demand stays low enough and local water resources are sufficient to meet the demand, neither scarcity nor dependency occurs, and transboundary cooperation is not needed. This point has been made in existing literature (e.g. related to social construction of scarcity) but is not yet widely recognised.

\subsection{Limitations and future work}

In our analysis, we used WWs, which refer to the total amount of water withdrawn, but not necessarily consumed, by each sector; much of which is returned to the water environment where it may be available to be withdrawn again. The return flows from industrial and domestic sectors have been taken into account in PCR-GLOBWB and the recycling ratios for industrial and domestic sectors have been estimated and validated at a country level based on Wada et al. (2011a, 2014). However, in this paper, estimation of return flows is uncertain and they may not necessarily be available to downstream users, for example because of pollution, timing of the flows, or infiltration to groundwater (Wada et al., 2011a). We therefore did not include return flows when calculating water stress, but those could be taken into account in the future.

EFRs (i.e. environmental flow requirements) are important in transboundary water management. The stress indicator used in the analysis includes EFRs, assuming $30 \%$ of the water is needed to satisfy the EFRs (Falkenmark et al., 2007). We do not account for EFR in a spatially disaggregated way as the analysis is conducted at the SBA scale, where spatially variable EFRs influence the dependency category, adding additional complexity to the transition map. EFRs are in any case a rather complex issue and not easy to quantify (Pastor et al., 2014). Global scale EFR methods could be criticised for not adequately capturing on-the-ground conditions - our treatment of environmental flows is fit for purpose given that our focus is on the resilience-based analytical framework.

Nuances of water availability were not taken into account in this analysis. Industrial or domestic pollution may occur in upstream parts of a basin, which might make water unusable for irrigation or domestic purposes (Thebo et al., 2017). Availability of green water has not been considered either. Green water increases the amount of locally available water by including soil water in addition to runoff. This affects scarcity, as the need for blue water should vary in response to changing green water availability, e.g. when there is less green water available, more blue water is needed. Decreases in availability of blue water (e.g. due to upstream withdrawals) may also push a region to use more green water. While green water is an important part of the local water availability, it does not affect inflows from upstream, by definition. Water is called "green water" when evapotranspiration occurs directly from rain or soil water, without runoff occurring. There is no additional effect on avail.natural, other than that on avail.local. Incorporating green water into the 
analysis will not affect avail.actual data either, as upstream withdrawals are in principle already accounted for in the water use model (including the effects of green water availability). The thresholds for both water shortage and stress are highly uncertain, so the effect of green water on the results is difficult to anticipate.

The main emphasis of the paper was the development of the analytical framework to understand the concept of upstream dependency from a resilience perspective. In this study, we provide the first attempt to link the dependency order to management strategies that could be taken to ease the possible scarcity situation. In future studies, in order to evaluate which transitions are actually plausible in the future, the analytical framework could also be applied to water availability and demand scenarios based on future climate change scenarios (representative concentration pathways, RCPs; Van Vuuren et al., 2011) as well as shared social pathway scenarios (SSP; O'Neill et al., 2014). In doing so, the scarcity criteria could also be revisited, given the simplicity of the indicators and thresholds used here, as acknowledged in Sect. 2.2.2. The analysis can be integrated with the concept of "adaptation tipping points (ATP)" to understand what strategies are needed (Kwadijk et al., 2010) to cope with the scarcity status. Additional insights may be gained using other thresholds and/or other water scarcity indicators, such as food self-sufficiency (Gerten et al., 2011; Kummu et al., 2014) or sustainability of water withdrawals (Wada and Bierkens, 2014). Future work could also quantify "distance" from a threshold, which would further address the distinction between how close these basins are to scarcity.

Our method was applied here at the basin scale, considering only international transboundary basins. It can, however, also be applied to understand the dependency at different scales to interpret, for example, more localised water dependencies, e.g. between states within countries (Garrick, 2015). Moreover, instead of using average water availability, analysis can be performed using water availability for each year to capture variability. Thus, the evolution of scarcity and dependency of an SBA for a given climate can be categorised into different transition pathways along which an SBA progresses as its water demand or water availability changes. An early attempt at this was made in the "discussion paper" version of this article (Munia et al., 2017). In connecting to management, the relevance of frequency of scarcity could be further examined in order to provide a more meaningful distinction between scarcity that occurs every year and scarcity that occurs in some year: at what frequency of scarcity do management options need to be implemented permanently rather than only adaptively e.g. trading of temporary vs. permanent water allocations (Bjornlund, 2003).

\section{Conclusions}

In this paper, we aimed to explore the relationships between SBAs (i.e. sub-basin areas) of global transboundary river basins, in terms of dependency of downstream on upstream inflows to meet water demand and avoid shortage and stress. Transboundary water dependency was examined through changes in scarcity category across different types of water availability (runoff, naturalised discharge, and actual discharge). We used the idea of regime shifts to illustrate the importance of dependency for basin management. The advantage of thinking in terms of thresholds is that we can reason about how scarcity and dependency might change in the future. In this paper, we focused on the effect of local demand and upstream water withdrawals, leaving possible changes in water availability, due to climate change for example, to future work. Understanding of the dependency category of an SBA has important policy implications regarding negotiation and redistribution of water among stakeholders, which may assist in improving water management in transboundary basins.

Data availability. Results of the analysis and sub-basin areas are provided in the Supplement. Input datasets are summarised in Table 2 , and water availability and water use data are available at http://hdl.handle.net/10411/UPKXSP (Wanders et al., 2018; Wada et al., 2011a, 2013).

Supplement. The supplement related to this article is available online at: https://doi.org/10.5194/hess-22-2795-2018-supplement.

Competing interests. The authors declare that they have no conflict of interest.

Acknowledgements. The work was financially supported by the Academy of Finland funded project WASCO (grant no. 305471), Emil Aaltonen Foundation funded project "eat-less-water", Maaja vesitekniikan tuki ry, and Academy of Finland SRC project "Winland". We highly appreciate the help and support of Olli Varis and our other team members. We are grateful for the careful comments of editor Pieter van der Zaag, and reviewers Erik Mostert and Erik Ansink.

Edited by: Pieter van der Zaag

Reviewed by: Erik Ansink and Erik Mostert 


\section{References}

Al-Faraj, F. A. and Scholz, M.: Impact of upstream anthropogenic river regulation on downstream water availability in transboundary river watersheds, Int. J. Water Resour. Dev., 31, 28-49, 2015.

Allan, J. A.: The Middle East water question: Hydropolitics and the global economy, Ib Tauris, London, 2002.

Beck, L., Bernauer, T., Siegfried, T. and Böhmelt, T.: Implications of hydro-political dependency for international water cooperation and conflict: Insights from new data, Polit. Geogr., 42, 23 33, 2014.

Bjornlund, H.: Farmer participation in markets for temporary and permanent water in southeastern Australia, Agr. Water Manage., 63, 57-76, 2003.

Brochmann, M. and Gleditsch, N.,P.: Shared rivers and conflict - A reconsideration, Polit. Geogr., 31, 519-527, 2012.

Brochmann, M., Hensel, P. R., and Tir, J.: International river treaty effectiveness, in: International Studies Association Annual Meeting, San Diego, CA, 2012.

Brown, A. and Matlock, M. D.: A review of water scarcity indices and methodologies, White Paper, 106, 19, 2011.

Degefu, D. M., He, W., Yuan, L., and Zhao, J. H.: Water allocation in transboundary river basins under water scarcity: a cooperative bargaining approach, Water Resour. Manage., 30, 44514466, 2016.

Delbourg, E. and Strobl, E.: Cooperation and conflict between upstream and downstream countries in African transboundary rivers, Ecole Polytechnique, France, 2012.

Döll, P.: Impact of climate change and variability on irrigation requirements: A global perspective, Climatic Change, 54, 269293, https://doi.org/10.1023/A:1016124032231, 2002.

Drieschova, A., Giordano, M., and Fischhendler, I.: Governance mechanisms to address flow variability in water treaties, Global Environ. Change, 18, 285-295, 2008.

Dukhovny, V.: Integrated Water Resources Management in Central Asia: The Challenges of Managing Large Transboundary Rivers, Global Water Partnership (GWP), Stockholm, Sweden, 2014.

Falkenmark, M., Berntell, A., Jägerskog, A., Lundqvist, J., Matz, M., and Tropp, H.: On the Verge of a New Water Scarcity: A Call for Good Governance and Human Ingenuity, SIWI Policy Brief., SIWI, Stockholm, 2007.

Garrick, D. E.: Water allocation in rivers under pressure: Water trading, transaction costs and transboundary governance in the Western US and Australia, Edward Elgar Publishing, Cheltenham, 2015.

Gerten, D., Heinke, J., Hoff, H., Biemans, H., Fader, M., and Waha, K.: Global water availability and requirements for future food production, J. Hydrometeorol., 12, 885-899, 2011.

Giordano, M. A. and Wolf, T. A.: Sharing Waters: Post Rio International Water Management, Natur. Resour. Forum, 27, 163-171, 2003.

Gleick, P. H.: Water, Drought, Climate Change, and Conflict in Syria, Weather Clim. Soc., 6, 331-340, 2014.

Grafton, R. Q., Libecap, G., McGlennon, S., Landry, C., and O'Brien, B.: An integrated assessment of water markets: a crosscountry comparison, Rev. Environ. Econ. Policy, 5, 219-239, 2011.

Green, O., Cosens, B., and Garmestani, A.: Resilience in transboundary water governance: the Okavango River Basin, Ecol. Soc., 18, https://doi.org/10.5751/ES-05453-180223, 2013.
Hoekstra, A. Y. and Chapagain, A. K.: Globalization of water: Sharing the planet's freshwater resources, Wiley-Blackwell, Oxford, UK, 2011.

Hoekstra, A. Y. and Mekonnen, M. M.: The water footprint of humanity, P. Natl. Acad. Sci. USA, 109, 3232-3237, 2012.

Jägerskog, A. and Zeitoun, M.: Getting Transboundary Water Right: Theory and Practice for Effective Cooperation, SIWI, Stockholm, 2009.

Klein Goldewijk, K., Beusen, A., and Janssen, P.: Long-term dynamic modeling of global population and built-up area in a spatially explicit way: HYDE 3.1, Holocene, 20, 565-573, https://doi.org/10.1177/0959683609356587, 2010.

Kummu, M., Ward, P. J., de Moel, H., and Varis, O.: Is physical water scarcity a new phenomenon? Global assessment of water shortage over the last two millennia, Environ. Res. Lett., 5, 034006, https://doi.org/10.1088/1748-9326/5/3/034006, 2010.

Kummu, M., Gerten, D., Heinke, J., Konzmann, M., and Varis, O.: Climate-driven interannual variability of water scarcity in food production potential: a global analysis, Hydrol. Earth Syst. Sci., 18, 447-461, https://doi.org/10.5194/hess-18-447-2014, 2014.

Kummu, M., Guillaume, J. H. A., De Moel, H., Eisner, S., Flörke, M., Porkka, M., Siebert, S., Veldkamp, T., and Ward, P. J.: The world's road to water scarcity: shortage and stress in the 20th century and pathways towards sustainability, Scient. Rep., 6, 38495, https://doi.org/10.1038/srep38495, 2016.

Kwadijk, J. C., Haasnoot, M., Mulder, J. P., Hoogvliet, M., Jeuken, A., van der Krogt, Rob, A. A., van Oostrom, N. G., Schelfhout, H. A., van Velzen, E. H., and van Waveren, H.: Using adaptation tipping points to prepare for climate change and sea level rise: a case study in the Netherlands, Wiley Interdisciplin. Rev.: Clim. Change, 1, 729-740, 2010.

Liu, J., Yang, H., Gosling, S. N., Kummu, M., Flörke, M., Pfister, S., Hanasaki, N., Wada, Y., Zhang, X., and Zheng, C.: Water scarcity assessments in the past, present, and future, Earth's Future, 5, 545-559, 2017.

Mehta, L.: The limits to scarcity: Contesting the politics of allocation, Routledge, Abingdon, UK, 2013.

Mirumachi, N.: Securitising shared waters: an analysis of the hydropolitical context of the Tanakpur Barrage project between Nepal and India, Geogr. J., 179, 309-319, 2013.

Mirumachi, N.: Transboundary water politics in the developing world, Routledge, Abingdon, UK, 2015.

Munia, H. A., Guillaume, J. H. A., Mirumachi, N., Porkka, M., Wada, Y., and Kummu, M.: Water stress in global transboundary river basins: significance of upstream water use on downstream stress, Environ. Res. Lett., 11, 014002, https://doi.org/10.1088/1748-9326/11/1/014002, 2016.

Munia, H. A., Guillaume, J., Mirumachi, N., Wada, Y., and Matti, K.: How downstream sub-basins depend on upstream inflows to avoid scarcity: typology and global analysis of transboundary rivers, Hydrol. Earth Syst. Sci. Discuss., https://doi.org/10.5194/hess-2017-537, in review, 2017.

Natural Earth: Admin 0 boundaries, http://www. naturalearthdata.com/downloads/50m-cultural-vectors/ 50m-admin-0-countries-2/, last access: 7 July 2017.

Nepal, S., Flügel, W. A., and Shrestha, A. B.: Upstreamdownstream linkages of hydrological processes in the Himalayan region, Ecol. Process., 3, 1-16, 2014. 
O’Neill, B. C., Kriegler, E., Riahi, K., Ebi, K. L., Hallegatte, S., Carter, T. R., Mathur, R., and van Vuuren, D. P.: A new scenario framework for climate change research: the concept of shared socioeconomic pathways, Climatic Change, 122, 387-400, 2014.

Pastor, A. V., Ludwig, F., Biemans, H., Hoff, H., and Kabat, P.: Accounting for environmental flow requirements in global water assessments, Hydrol. Earth Syst. Sci., 18, 5041-5059, https://doi.org/10.5194/hess-18-5041-2014, 2014.

Porkka, M., Kummu, M., Siebert, S., and Flörke, M.: The role of virtual water flows in physical water scarcity: the case of Central Asia, Int. J. Water Resour. Dev., 28, 453-474, 2012.

Scott, C. A., El-Naser, H., Hagan, R. E. ,and Hijazi, A.: Facing Water Scarcity in Jordan, Water Int., 28, 209-216, 2003.

Song, J. and Whittington, D.: Why have some countries on international rivers been successful negotiating treaties? A global perspective, Water Resour. Res., 40, W05S06, https://doi.org/10.1029/2003WR002536, 2004.

Thebo, A. L., Drechsel, P., Lambin, E. F., and Nelson, K. L.: A global, spatially-explicit assessment of irrigated croplands influenced by urban wastewater flows, Environ. Res. Lett., 12, 074008, https://doi.org/10.1088/1748-9326/aa75d1, 2017.

UN Water: The Global Opening of the 1992 Water Convention, United Nations Economic Commission for Europe, New York, Geneva, 2013.

UN Watercourses Convention: Article 7, 7.1.2 Significant harm, available at: http://www.unwatercoursesconvention. org/the-convention/part-ii-general-principles/

article-7-obligation-not-to-cause-significant-harm/

7-1-2-significant-harm/, last access: 13 March 2018.

Van Vuuren, D. P., Edmonds, J., Kainuma, M., Riahi, K., Thomson, A., Hibbard, K., Hurtt, G. C., Kram, T., Krey, V. and Lamarque, J.: The representative concentration pathways: an overview, Climatic Change, 109, 5-31, https://doi.org/10.1007/s10584-0110148-z, 2011.

Veldkamp, T. I. E., Wada, Y., Aerts, J C J H, Doll, P., Gosling, S. N., Liu, J., Masaki, Y., Oki, T., Ostberg, S., Pokhrel, Y., Satoh, Y., Kim, H., and Ward, P. J.: Water scarcity hotspots travel downstream due to human interventions in the 20th and 21st century, Nat. Commun., 8, 15697, https://doi.org/10.1038/ncomms15697, 2017.
Wada, Y. and Bierkens, M. F.: Sustainability of global water use: past reconstruction and future projections, Environ. Res. Lett., 9, 104003, https://doi.org/10.1088/1748-9326/9/10/104003, 2014.

Wada, Y., van Beek, L. P. H., and Bierkens, M. F. P.: Modelling global water stress of the recent past: on the relative importance of trends in water demand and climate variability, Hydrol. Earth Syst. Sci., 15, 3785-3808, https://doi.org/10.5194/hess-15-37852011, 2011a.

Wada, Y., van Beek, L. P. H., Viviroli, D., Dürr, H. H., Weingartner, R., and Bierkens, M. F. P.: Global monthly water stress: 2. Water demand and severity of water stress, Water Resour. Res., 47, W07518, https://doi.org/10.1029/2010WR009791, 2011b.

Wada, Y., van Beek, L. P. H., Wanders, N., and Bierkens, M. F. P.: Human water consumption intensifies hydrological drought worldwide, Environ. Res. Lett., 8, 1-14, https://doi.org/10.1088/1748-9326/8/3/034036, 2013.

Wada, Y., Wisser, D., and Bierkens, M. F. P.: Global modeling of withdrawal, allocation and consumptive use of surface water and groundwater resources, Earth Syst. Dynam., 5, 15-40, https://doi.org/10.5194/esd-5-15-2014, 2014.

Walker, B., Holling, C. S., Carpenter, S., and Kinzig, A.: Resilience, adaptability and transformability in social-ecological systems, Ecol. Soc., 9, 5, https://doi.org/10.5751/ES-00650090205, 2004

Wanders, N., Wada, Y., Van Beek, R. and Bierkens, M. F. P.: Original data for study on Human water consumption intensifies hydrological drought worldwide, Dataverse NL, V1, http: //hdl.handle.net/10411/UPKXSP, last access: 13 March 2018.

Wolf, A. T.: Conflict and cooperation along international waterways, Water Policy, 1, 251-265, 1998.

Wolf, A. T.: Criteria for equitable allocations: the heart of international water conflict, Nat. Resour. Forum, 23, 3-30, https://doi.org/10.1111/j.1477-8947.1999.tb00235.x, 1999.

Wolf, A. T.: Shared waters: Conflict and cooperation. Annu. Rev. Environ. Resour., 32, 241-269, 2007.

Wolf, A. T., Yoffe, S. B., and Giordano, M.: International waters: identifying basins at risk, Water Policy, 5, 29-60, 2003. 